\title{
Older doctors under increasing regulatory scrutiny
}

$\mathrm{C}$ anada's regulatory colleges are focusing more and more attention on older physicians, says the Canadian Medical Protective Association (CMPA). "It's simply the colleges' interest in ensuring fitness to practise," says Dr. Todd Watkins, the association's managing director of physician services.

The CMPA, which provides medical liability protection for more than 92000 doctors, addressed the issue in a recent article in its Perspective magazine. The article opens with this caution: "As physicians age, there is increasing attention on their ongoing clinical competency by medical regulatory authorities (colleges) and others."

The College of Physicians and Surgeons of Ontario (CPSO), for example, routinely conducts random peer assessments of physicians who have been in independent practice for at least five years and who are under the age of 70 . Once doctors turn 70, however, peer assessment is mandatory (if not done within the previous five years) and is conducted every five years. According to the college's most recent data, $88 \%$ of physicians under 70 who were randomly selected for an assessment received a satisfactory result. In comparison, $79 \%$ of physicians targeted for an assessment at age 70 received a satisfactory result. According to the 2014 National Physician Survey, 16.4\% of working Canadian physicians are 65 years of age or older.

"While age is a trigger for conducting individualized testing, subsequent decisions about the individual are based on their own competence, and not based on generalizations about their age," notes CPSO spokesperson Tracey Sobers.

Poor, illegible or incomplete recordkeeping are among the problems. Other issues include lack of knowledge about current guidelines, failure to keep current with immunizations or medications, and lagging continuing professional development. Cognition and clinical judgment are also potential concerns.

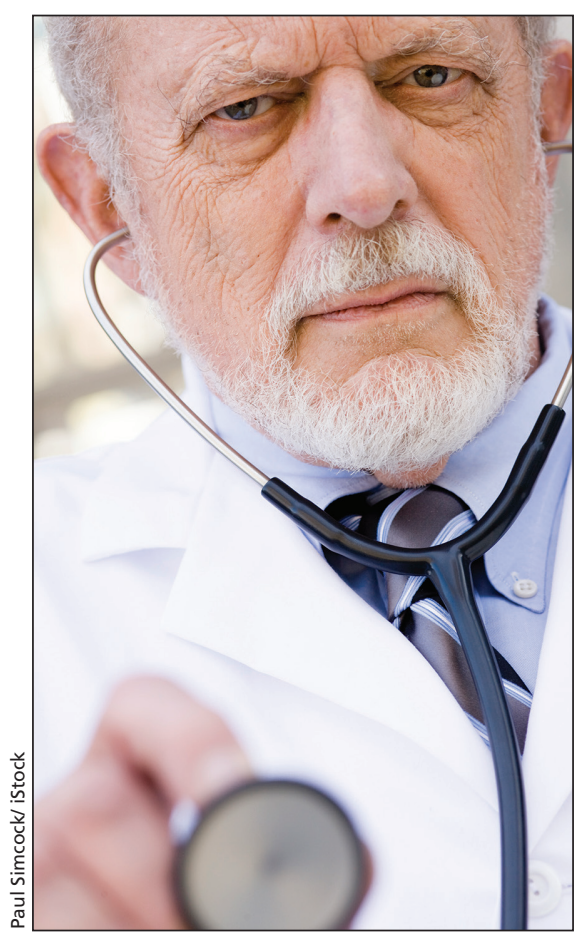

Poor or illegible record-keeping is one problem among older physicians.

The CMPA advises aging physicians and their colleagues to be familiar with the main issues associated with working later in life, "including the key medical-legal risks, and how to support the ongoing delivery of safe medical care."

"It makes sense with this age group that there might be more challenges," says Dr. Gordon Wallace, the managing director of the CMPA's Safe Medical Care Group. Colleagues of older physicians are also encouraged to be aware of the increased regulatory interest and potential problems.

Not all provincial colleges are taking a closer look at older physicians, however. Donna Call, spokesperson for the College of Physicians and Surgeons of Alberta, says it "treats all members the same, not distinguishing for scrutiny or programming because of age."

The College of Physicians and Surgeons of New Brunswick instituted a peer review program almost 20 years ago. Registrar Dr. Ed Schollenberg says "there was quite a carnage for a while but we just rarely see docs working longer than they should now. Most of our senior docs abandon full time practice and do other things."

Issues with aging doctors have not been widespread, but they can be thorny, Schollenberg points out. "Lack of insight, maybe financial pressure to stay in the game, and familial longevity" may be factors with some older physicians.

It appears Canada will not follow in the footsteps of the United States, where the American Medical Association (AMA) is developing competency guidelines aimed at ensuring older doctors are still able to treat patients safely. At its 2015 annual meeting, in a vote without debate, the AMA agreed to the new guidelines. They were based on a report by its Council on Medical Education that highlighted the risks that come with aging and the need for "periodic re-evaluation after a certain age such as 70, when incidence of declines is known to increase."

The Royal College of Physicians and Surgeons of Canada has launched Competence by Design, a nine-year initiative to improve specialist training and lifelong learning that will culminate in 2022. The program focuses on outcomes, asking the question: "What abilities do physicians need at each stage of their career?" It organizes physician training around desired outcomes and looks at the required competencies.

Older physicians may have different, even more difficult, issues than their younger colleagues, but many of these can be resolved to everyone's satisfaction, notes Sobers. "While, to some degree, age is a predictor for a lower assessment grade for some physicians, our experience has shown that most physicians in this age group are able to improve their practices with intervention." - donalee Moulton, Halifax, NS

With files from Arianna Danganan, CMAJ

CMAJ 2016. DOI:10.1503/cmaj.109-5298 